\title{
ANÁLISE DAS PROPRIEDADES DO CONCRETO ESTRUTURAL UTILIZANDO A CINZA PESADA DO BAGAÇO DA CANA-DE AÇÚCAR
}

\section{ANALYSIS OF PROPERTIES OF STRUCTURAL CONCRETE USING THE HEAVY SUGARCANE BAGASSE ASH}

Laís Sant'Ana Braga ${ }^{1}$; Maria Victória Bello Padovam dos Santos ${ }^{1}$; Daniele Araújo Altran²; Filipe Bittencourt Figueiredo ${ }^{3}$

\footnotetext{
${ }^{1}$ Discentes da Universidade do Oeste Paulista. ${ }^{2}$ Docente da Universidade do Oeste Paulista. ${ }^{3}$ Docente da Universidade Federal da Grande Dourados. e-mail: lais-santanna@hotmail.com; victoria_padovam@hotmail.com; daniele@unoeste.br; eng.filipebittencourt@gmail.com;
}

RESUMO - O Brasil lidera hoje como o maior produtor de etanol e açúcar no mundo, sendo consequentemente o maior produtor de canade-açúcar. Com isso, para tamanha produção, são gerados grandes volumes de resíduos que se buscam empregá-los para a redução do volume de descarte no meio ambiente. O bagaço é o resíduo da produção de etanol e açúcar, em que é empregado para a cogeração de energia elétrica do qual resulta um resíduo final: as cinzas. As mesmas são descartadas em aterros ocupando um grande volume e gerando um maior impacto ambiental. Este trabalho tem como objetivo confeccionar o concreto com substituição parcial de agregado miúdo pelas cinzas pesadas do bagaço da cana-de-açúcar, com diferentes teores de substituição $(0 \%, 10 \%, 20 \%, 30 \%$ e $40 \%)$, em massa. Os concretos foram caracterizados no estado fresco quanto à consistência, e no estado endurecido quanto a resistência à compressão e absorção de água. Os resultados constatam que a substituição da areia por Cinzas do Bagaço de Cana-de-açúcar ( $C B C$ ) foram satisfatórios visto que, quanto maior quantidade de $\mathrm{CBC}$ mais resistência à ruptura foi apresentada.

Palavras-chave: cinzas; concreto; resíduo.

ABSTRACT - Nowadays Brazil the leading producer of ethanol and sugar in the world, and is therefore the largest producer of sugarcane. Thereby, for such large production, large volumes of waste are created and we seek to use them to reduce the volume of waste in the environment. Bagasse is the residue from the production of ethanol and sugar, and it is used for the cogeneration of electric energy which results in a final residue: the ashes. Those ashes are discarded in landfills occupying a large volume and generating a larger environmental impact. This work has the objective of making concrete with partial substitution of small aggregate by the heavy ash of the sugarcane bagasse, with different levels of substitution ( $0 \%, 10 \%, 20 \%, 30 \%$ and $40 \%)$, by mass. The concretes were characterized in the fresh condition for consistency, and in the hardened condition for the compressive strength and water 
sugarcane bagasse ash (BCC) was satisfactory, since the greater the amount of BCC plus resistance of rupture.

Keywords: ashes; concrete; residue.

\section{INTRODUÇÃO}

Atualmente, o Brasil é um dos maiores produtores de cana-de-açúcar no mundo, seguido por Índia e China, sendo uma das principais culturas da economia brasileira. Em um levantamento da safra de 2015/16 estima-se uma produção de 654,6 milhões de toneladas de cana-de-açúcar em uma extensão territorial com um pouco mais de 9 milhões de hectares (CONAB, 2015). O cultivo é destinado, principalmente, à produção de açúcar e etanol, sendo responsável por mais de $50 \%$ do açúcar comercializado mundialmente, segundo o Ministério de Agricultura Pecuária e Abastecimento (BRASIL, Ministério da Agricultura, 2012).

Dentre os processos em que a canade-açúcar é submetida para a produção de açúcar e álcool, destaca-se o processo de moagem onde é realizada a extração do caldo, resultando um material denominado de bagaço. Esse material é aplicado como combustível para caldeira, produção de celulose e na alimentação de gado confinado (ALCARDE, 2009).

A queima do bagaço e resíduos em caldeiras gera energia elétrica, o suficiente para fornecer à própria usina e até pequenas comunidades. Segundo Hojo e Martins (2015) além da energia elétrica gerada, a queima do bagaço também resulta num material chamado de cinzas, podendo ser subdividas em cinzas pesadas e cinzas volantes (leves), oriundos, respectivamente, do fundo das fornalhas e do lavador de gases atrelados à chaminé.

Com base nessas informações, tem-se que a queima do bagaço da cana de açúcar resultará em média $25 \mathrm{Kg}$ de cinzas por tonelada de bagaço. Isso se torna uma quantidade bem significativa quando a incineração do bagaço resulta em 3,8 milhões de toneladas de cinzas por ano, sendo parte dela usada como adubo nas próprias plantações - embora haja controversas sobre sua eficiência -, e outra sendo descartada em aterros sanitários, ocupando um grande volume e possíveis danos ao solo e em recursos hídricos (SALES; LIMA, 2010).

Estudos apontam a eficiência das cinzas volantes na substituição parcial do cimento Portland no concreto, por ser um material pozolânico, ou seja, com uma alta quantidade de dióxido de silício que, em contato com hidróxido de cálcio - como a cal hidratada - à temperatura ambiente ganham propriedades cimentícias (TORRES et al., 2010). Todavia, o estudo em si deste trabalho é a viabilidade da utilização das cinzas 
pesadas como substituição parcial do agregado miúdo (areia) no concreto, já que a mesma possui algumas características semelhantes à areia, como menor massa específica e maior absorção de água.

\section{JUSTIFICATIVA}

Segundo a Federação da Indústria de São Paulo (FIESP, 2001) o valor médio é de $260 \mathrm{~kg}$ de resíduo seco de bagaço por tonelada de cana produzida, a fim de se estabelecer uma média estimativa de geração de resíduos de bagaço, em que cerca de $95 \%$ dos resíduos de bagaço gerados são queimados em caldeiras para produção de energia, onde é considerado o valor de $6 \mathrm{Kg}$ cinza/250 Kg de bagaço de cana que alimenta a caldeira.

Com a grande geração desse resíduo, nada melhor que empregá-lo na produção de concreto convencional, formado pela mistura devidamente proporcionada de um aglomerante (cimento Portland), agregados (miúdos e graúdos) e água, sendo os agregados responsáveis por $85 \%$ do peso do concreto, portanto, a parte constituinte de maior volume, segundo Cavalcanti e Parahyba (2012). Com isso, o trabalho visa o estudo da eficácia da substituição parcial das cinzas como agregado miúdo no concreto estrutural, dando uma destinação viável, econômica e ambiental, para este resíduo concomitante à redução da mineração da areia em leitos de rios que, de acordo com Valverde (2001), é responsável por 90\% da produção brasileira, no qual no Estado de São Paulo, a relação é de: $45 \%$ proveniente de várzeas, $35 \%$ de leitos de rios e o restante de outras fontes.

Neste contexto, esse trabalho vai na direção do estudo da redução de impactos ambientais em duas vertentes. Por um lado, pelo aproveitamento de um resíduo industrial, gerado, principalmente, na fabricação do etanol, e por outro pela substituição de parte do agregado miúdo, que são responsáveis por impactos ambientais negativos muitas vezes irreversíveis. Incluindo que segundo Gurgel (2012) as cinzas oriundas da queima do bagaço nas caldeiras são dispostas em áreas de aterro ou aplicadas no solo, são gerados em média 2,06 kg/tonelada de cana, com esse dado a pesquisa supre o destino final desse material.

\section{OBJETIVOS}

Este trabalho tem como objetivo o desenvolvimento da moldagem de corpos de prova de concreto, que foi substituído parcialmente o agregado miúdo de areia por cinza pesada do bagaço da cana-de-açúcar. Sendo este considerado como um novo material na composição do concreto para utilização na produção de elementos estruturais, incorporando o concreto 
convencional para que possua características físicas e mecânicas semelhantes ou melhoradas se comparada à mesma, suprindo as exigências estabelecidas na ABNT NBR 6118:2014, sendo uma alternativa viável economicamente e ambientalmente, com intuito de apresentar como objetivos específicos:

- Análise da cinza pesada do bagaço da cana-de-açúcar coletada na usina Dracena em sua unidade de Dracena SP, para caracterizar suas propriedades físicas através dos ensaios de absorção de água, composição granulométrica e massa específica;

- Análise de novos traços de concreto com a substituição gradativa de $10 \%$ em $10 \%$ da areia pela cinza pesada do bagaço da cana-de-açúcar;

- Realizar ensaios para analisar suas propriedades mecânicas, a fim de atingir as recomendações das normas: resistência mecânica à compressão, consistência e absorção de água;

- Verificar a classificação estrutural dos traços de concreto com a utilização da cinza pesada do bagaço da cana-deaçúcar.

\section{MATERIAIS E MÉTODOS}

A execução do concreto dá-se, primeiramente, através dos ensaios dos materiais que será utilizado. Este mesmo é composto de cimento Portland, água, areia e cinza pesada, como agregado miúdo; e rocha britada, como agregado graúdo. Os ensaios necessários para se obter os resultados, serão baseados nas Normas Brasileiras (NBR) da Associação Brasileira de Normas Técnicas (ABNT) - órgão este de utilidade pública responsável pela normalização técnica no Brasil elaboradas por seus Comitês Brasileiros (ABNT/CB), Organismos de Normalização Setorial (ABNT/ONS) e Comissões de Estudo Especiais (ABNT/CEE).

O aglomerante cimento portland é composto basicamente de clínquer e gesso. O clínquer é uma mistura de argila e calcário (rocha de carbonato de cálcio e magnésio). Esses dois materiais são levados a um forno na temperatura de $1450^{\circ} \mathrm{C}$ onde se fundem formando bolotas denominadas de clínquer, responsável esta pela resistência mecânica do material resultante. Já o gesso é acrescentado posteriormente ao clínquer no processo da moagem até os dois virarem pó, sendo o gesso responsável por controlar o processo de endurecimento do cimento em contato com a água, chamado de início de pega, visto que sem este material o endurecimento do cimento seria instantâneo assim que o hidratasse (PEREIRA et al., 2013). 
Os materiais areia e brita (agregado miúdo e agregado graúdo, respectivamente) podem ser entendidos por materiais granulares em que não possuem forma nem volumes determinados, sendo a maioria materiais inertes, com dimensões e propriedades adequadas para utilizar-se em obras de engenharia, obtidos na natureza como em leitos de rios e em rochas britadas ou fragmentos rolados. Por serem materiais inertes, a sua utilização no concreto não prejudica a resistência aos esforços mecânicos e melhora algumas propriedades mecânicas como a retração e resistência ao desgaste por abrasão (TEODORO, 2013).

A CBC coletada para essa pesquisa foi a da Usina Dracena na sua unidade de Dracena - SP. A cinza obtida originou-se de um processo de queima onde a temperatura varia de 500 a 750 ㅇ C segundo a companhia. A CBC foi coletada na etapa final quando a cinza é levada para ser usada como adubo. A cinza utilizada foi a pesada que possui características físicas que se assemelham a areia, como a textura normalmente grossa, fundida e vítrea, sendo uma mescla de materiais agregados e particulados de mineralogia sílico-aluminosas e de textura areno-siltosa. Segundo Silva (2006) a cinza pesada é resultante da queima do bagaço da cana-de-açúcar, coletada nos fundos das fornalhas e gaseificadores, no qual é conduzida hidraulicamente para tanques de decantação, por conseguinte apresenta um teor de umidade de até $30 \%$ do peso.

Inicialmente foi realizado o ensaio da determinação da composição granulométrica, de acordo com a NBR 7181:1988 da ABNT em que prescreve o método a ser seguido para tal determinação, não apenas da $\mathrm{CBC}$, mas de todos os agregados empregados (areia e brita). É feita através do processo de peneiramento dos materiais originando às curvas granulométricas. Por meio deste processo são obtidos:

- Diâmetro Máximo Característico: de acordo com a NBR7211:2009 da ABNT o diâmetro máximo característico (DMC) é a grandeza associada a distribuição granulométrica do agregado correspondente à abertura, em milímetros, da malha da peneira em que foi retida uma porcentagem acumulada igual ou inferior a $5 \%$ de sua massa;

- Módulo de Finura: de acordo com a NBR 7211:2009 da ABNT, o módulo de finura é a somatória da porcentagem acumulada de um determinado material, em massa, na série de peneira normal, dividida por 100. Seu objetivo principal é a separação dos agregados em séries de mesmo módulo de finura, para controlar os agregados de mesma procedência.

- Coeficiente de Uniformidade: esta análise apresenta uma diversidade da 
dimensão das partículas do material em estudo na qual é diretamente proporcional à inclinação da curva granulométrica do mesmo, que de acordo com a NBR 6502:1995 da $A B N T$, quanto mais inclinada a curva granulométrica, mais graduações diferentes possui o material.

- Coeficiente de Curvatura: esse coeficiente indica o contorno da curva viabilizando a detecção de descontinuidades no conjunto.

O teor de umidade foi determinado de acordo com a ABNT NBR 6457:1986 para se obter o valor do teor de umidade de cada amostra, em porcentagem, apresentando a quantidade de água presente nas amostras em estado natural em relação às amostras secas. Esse ensaio se faz necessário para a obtenção da massa específica dos materiais empregados no concreto (areia, CBC, cimento e brita), segundo a norma da ABNT NBR 6508:1984, que prescreve o método para a determinação da massa específica dos grãos de solos que passam na peneira de 4,8 $\mathrm{mm}$, por meio de picnômetro.

O ensaio da "Determinação da consistência pelo abatimento do tronco de cone" (ABNT NBR NM 67:1998), conhecido como "Teste de queda" tem por função determinar a consistência do concreto fresco por meio da medida de seu assentamento em concretos que apresentem plasticidade e coesão. Esse assentamento deve ser igual ou superior a $10 \mathrm{~mm}$ em relação à altura do cone.

Os ensaios de moldagem e cura dos corpos-de-prova foram realizados segundo a ABNT NBR 5738:2015 “Concreto - Procedimento para moldagem e cura de corpos-deprova" e emenda ABNT NBR 5738:2008. Seguindo a norma foram feitas as moldagens dos corpos-de-prova, em que o mesmo ficou por $24 \mathrm{~h}$ no molde, depois desse tempo conservou-se em câmara úmida até a idade de ruptura com 7, 14 e 28 dias.

Para a absorção de água do concreto endurecido, na condição saturados superfície seca, o ensaio foi regido pela ABNT NBR 9778:2009 "Argamassa e Concreto endurecidos - Determinação da absorção de água por imersão - Índice de vazios e massa específica".

$E$, para o ensaio de obtenção de resistência de ruptura máxima à compressão no concreto foi regida pela ABNT NBR 5739:2007 - Ensaio de compressão de corpos-de-prova cilíndricos -, cuja norma brasileira serve como parâmetro para a execução de rupturas de corpos de prova padronizados de concreto e, por conseguinte interpretação dos seus resultados, em que foi realizada até a sua cura.

A substituição da areia pela CBC foi com proporções de $0 \%, 10 \%, 20 \%, 30 \%$ e $40 \%$, sendo moldados 10 corpos de prova cilíndricos para cada traço $(10 \mathrm{~cm}$ de 
diâmetro por $20 \mathrm{~cm}$ de altura), sendo 9 deles submetidos ao ensaio de resistência de ruptura máxima à compressão e 1 ao ensaio de absorção de água no concreto endurecido, para verificação do comportamento desse novo elemento na composição do concreto.

A escolha do traço de concreto foi desenvolvida por Silva (1975), conforme apresentado na Tabela 1, sendo para atingir uma resistência à ruptura de $20 \mathrm{MPa}$ aos 28 dias de sua confecção, sem nenhum aditivo, de modo a ser de uso geral e usando os materiais comuns que são cimento, areia, brita e água.

Tabela 1. Composição do Concreto para $1 \mathrm{~m}^{3}$.

\begin{tabular}{c|c}
\hline Material & Quantidade \\
\hline Brita 1 & $1038 \mathrm{~kg}$ \\
\hline Areia (seca) & $791 \mathrm{~kg}$ \\
\hline Cimento & $302 \mathrm{~kg}$ \\
\hline Água & $211 \mathrm{~kg}$ \\
\hline Fator A/C & $0,70 \%$
\end{tabular}

Fonte: (SILVA, 1975).

Foram feitos ajustes devido à massa específica dos materiais do laboratório ser diferentes da referência, ocorrendo também com o fator água-cimento devido ao teor de umidade levando em consideração dos materiais estarem úmidos e influenciarem na trabalhabilidade e resistência à ruptura do concreto, assim dimensionados para 10 corpos de prova com um volume de 0,25 litros para cada traço, descrito conforme Tabela 2.

Tabela 2. Composição dos Traços

\begin{tabular}{c|c|c|c|c|c}
\hline & \multicolumn{5}{|c}{ Quantidade } \\
\hline Material & Piloto & $10 \%$ & $\mathbf{2 0 \%}$ & $\mathbf{3 0 \%}$ & $\mathbf{4 0 \%}$ \\
\hline $\begin{array}{c}\text { Brita 1 } \\
\text { (kg) }\end{array}$ & 27,81 & 27,81 & 27,81 & 27,81 & 27,81 \\
\hline $\begin{array}{c}\text { Areia } \\
\text { (kg) }\end{array}$ & 19,625 & 17,933 & 15,941 & 13,948 & 11,955 \\
\hline $\begin{array}{c}\text { CBC (kg) } \\
\text { Cimento } \\
\text { (kg) }\end{array}$ & - & 2,643 & 5,287 & 7,93 & 10,547 \\
\hline Água (kg) & 4,545 & 4,545 & 4,545 & 4,545 & 4,545 \\
\hline Fator A/C & $0,60 \%$ & $0,60 \%$ & $0,60 \%$ & $0,60 \%$ & $0,60 \%$ \\
\hline
\end{tabular}

Fonte: (SILVA, 1975).

\section{RESULTADOS E DISCUSSÕES}

Primeiramente realizou-se o ensaio de granulometria (Figura 1), tanto para a areia quanto para a CBC de mesma massa, como segue nas Tabelas 3 e 4 .

Tabela 3. Granulometria da areia

\begin{tabular}{c|c|c|c|c}
\hline \multicolumn{5}{c}{ Granulometria Areia } \\
\hline ABNT & (mm) & $\begin{array}{c}\text { Massa } \\
\text { (g) }\end{array}$ & $\begin{array}{c}\text { retida } \\
\text { \% acumulada }\end{array}$ \\
\hline 4 & 4,76 & 6,5 & 1,3 & 1,3 \\
\hline 8 & 2,38 & 17,7 & 3,5 & 4,9 \\
\hline 16 & 1,19 & 53,4 & 10,7 & 15,5 \\
\hline 30 & 0,59 & 134,4 & 26,9 & 42,4 \\
\hline 50 & 0,30 & 199,5 & 39,9 & 82,3 \\
\hline 100 & 0,149 & 79,9 & 16,0 & 98,3 \\
\hline 200 & 0,074 & 6,4 & 1,3 & 99,6 \\
\hline Fundo & $<$ & 2,1 & 0,4 & 100,0 \\
\hline
\end{tabular}

Fonte: Autores. 
Tabela 4. Granulometria da CBC

\begin{tabular}{c|c|c|c|c}
\hline \multicolumn{5}{|c}{ Granulometria CBC } \\
\hline ABNT & $(\mathbf{m m})$ & $\begin{array}{c}\text { Massa } \\
\text { (g) }\end{array}$ & $\begin{array}{c}\text { retida } \\
\text { \% acumulada }\end{array}$ \\
\hline 4 & 4,76 & 0 & 0,00 & 0,00 \\
\hline 8 & 2,38 & 0,06 & 0,01 & 0,01 \\
\hline 16 & 1,19 & 2,45 & 0,49 & 0,50 \\
\hline 30 & 0,59 & 10,85 & 2,17 & 2,67 \\
\hline 50 & 0,3 & 38,6 & 7,72 & 10,42 \\
\hline 100 & 0,149 & 259,08 & 51,82 & 62,24 \\
\hline 200 & 0,074 & 131,58 & 26,32 & 88,56 \\
\hline Fundo & $<$ & 57,38 & 11,48 & 100,00 \\
\hline
\end{tabular}

Fonte: Autores.

Figura 1. Curva granulométrica da areia e da $C B C$

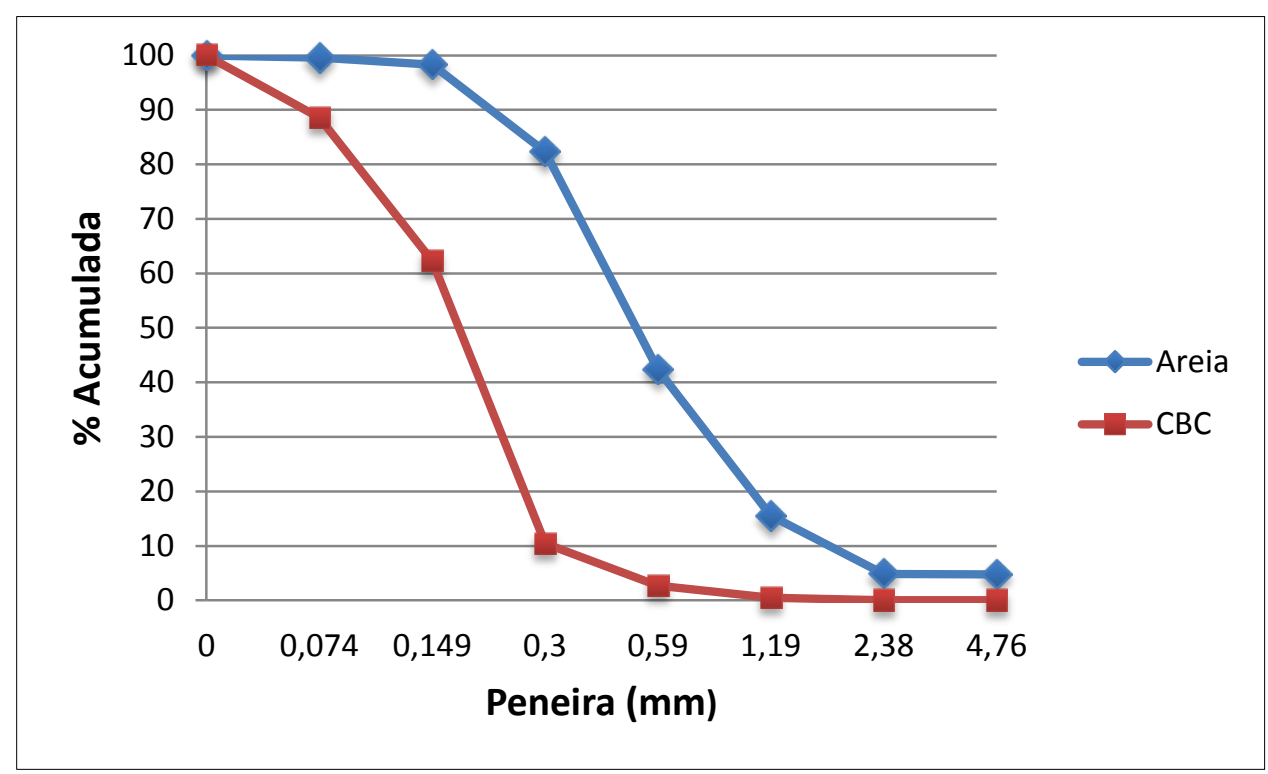

Fonte: Autores (2017).

A partir da curva granulométrica

(Figura 1) da areia e CBC conforme a classificação da ABNT NBR 6502:1995, conclui-se que a maior parte da massa retida da areia está na peneira 30 e 50. Já a CBC a maior parte retida está na peneira 100 e 200, devido apresentar maior quantidade de finos na sua composição.

Depois da realização do processo de peneiramento da $C B C$ no vibrador, verificouse uma pequena perda da mesma quando aferiu-se a massa retida em cada peneira. Por a $\mathrm{CBC}$ ser um material muito fino, quando 
submetida à vibração ela entrou em suspensão passando por entre as peneiras e perdendo-se no ar. Para efeito de cálculo e construção da curva granulométrica, o material particulado foi considerado como material retido no filer, passando então pela peneira 200 e depositando-se no fundo.

Foi determinado o teor de umidade de cada amostra para efeito de cálculo, de acordo com a norma ABNT NBR 6457:1986. Com isso constatou-se que há pouca presença de água nas amostras analisadas, sendo a CBC o maior valor em relação aos outros materiais, atingindo $1,03 \%$ devido a sua maior exposição às intempéries (Tabela 5). Contudo, o teor de umidade da mesma é totalmente satisfatório visto que é um valor relativamente baixo e próximo do teor de umidade do material substituinte.

Tabela 5. Teor de umidade dos materiais

\begin{tabular}{c|c}
\hline Material & $\begin{array}{c}\text { Teor de Umidade } \\
\mathbf{( \% )}\end{array}$ \\
\hline Areia & 0,1 \\
\hline CBC & 1,03 \\
\hline Cimento & 0,53 \\
\hline
\end{tabular}

Fonte: Autores.

Em posse dos resultados do teor de umidade, realizou-se o ensaio de massa específica no picnômetro no laboratório da UNOESTE de acordo com a norma ABNT NBR 6508:1984. À priori foram determinados os valores da massa específica de cada material a ser utilizado na confecção do concreto desenvolvido por Silva (1975), como valorespilotos dos materiais (Tabela 6). Contudo, executaram-se os ensaios de massa específica de cada material para efeitos comparativos e uma provável correção dos mesmos, conforme Tabela 7.

Tabela 6. Massa Específica utilizada por Silva

\begin{tabular}{|c|c|}
\hline Material & $\begin{array}{c}\text { Massa específica } \\
\qquad(\mathrm{kg} / \mathrm{l})\end{array}$ \\
\hline Brita 1 & 2,65 \\
\hline Areia (seca) & 2,64 \\
\hline Cimento & 3,15 \\
\hline Água & 1,01 \\
\hline
\end{tabular}

Tabela 7. Massa Específica dos materiais da UNOESTE

\begin{tabular}{c|c}
\hline Material & $\begin{array}{c}\text { Massa específica } \\
\mathbf{( k g / l )}\end{array}$ \\
\hline Brita 1 & 2,84 \\
\hline Areia (seca) & 2,62 \\
\hline Cimento & 3,15 \\
\hline Água & 1,01 \\
\hline CBC & 1,99 \\
\hline
\end{tabular}

Fonte: Autores.

Com resultados obtidos em posse, constatou-se a diferença de valores entre a massa específica da areia e do material substituinte $(C B C)$, que se dá devido a $C B C$ possuir maior quantidade de partículas finas 
em sua composição, tornando-a mais leve que a areia, contudo, ambas sofreram correções. Para a brita também foi necessário corrigir a massa específica na confecção do traço já que o valor obtido apresentou-se maior que o padrão adotado. Já o cimento foi apresentado o mesmo valor que o valor proposto por Silva (1975), sendo assim não foi necessário sua correção.

De acordo com a norma da ABNT NBR 7211:2009 determinou-se o Diâmetro Máximo Característico (DMC) e o Módulo de Finura (MF) da areia e da CBC. Pode-se observar que o DMC da areia foi maior que o da $\mathrm{CBC}$, isso porque as partículas desse material são mais grossas atingindo a uma porcentagem retida acumulada de 5\% (ou imediatamente inferior) rapidamente (Tabela 8). O mesmo acontece no Módulo de Finura, em que quanto maior o MF mais grosso será o material, justificando o resultado obtido em que temos a areia média como o material de partículas mais grossas em relação à CBC.

Tabela 8. Determinação do DMC e MF da areia e da CBC

\begin{tabular}{c|c|c}
\hline Características & Areia & CBC \\
\hline DMC & 2,38 & 0,59 \\
\hline MF & 2,447 & 0,758 \\
\hline
\end{tabular}

Fonte: Autores.

A determinação do Coeficiente de Uniformidade (U) se deu através da norma ABNT NBR 6502:1995, em que classificou-se a uniformidade dos grãos. Tanto a areia quanto a $C B C$ apresentou-se como uniformes (Tabela 9), já que seus resultados enquadrouse entre o parâmetro de 0 a 5. Quanto ao Coeficiente de Curvatura (CC) é calculado para fornecer a ideia do formato da curva granulométrica em que nos permite detectar descontinuidades do conjunto. Com isso pôde-se observar que a CBC foi considerada bem graduada devido seu resultado de 1,2 estar dentro do parâmetro $1<\mathrm{CC}<3$. Já a areia apresentou-se com um valor de 0,92, enquadrando-se no parâmetro $\mathrm{CC}<1$, para solos mal graduados, ou seja, a areia utilizada não possui quantidades de partículas finas necessárias para preencher os espaços vazios e ser considerado um solo bem graduado (Tabela 9).

Tabela 9. Determinação do U e CC da areia e CBC

\begin{tabular}{c|c|c}
\hline Aspecto & Areia & CBC \\
\hline Uniformidade & Uniforme & Uniforme \\
\hline Distribuição & Mal graduada & Bem \\
granulométrica & & graduada \\
\hline
\end{tabular}

Fonte: Autores.

Quanto ao abatimento do concreto, esse tópico abrange uma comparação entre o concreto convencional e o concreto com $\mathrm{CBC}$ a fim de demonstrar a trabalhabilidade de cada traço apresentado, conforme Tabela 10. 
Tabela 10. Relação Traço de concreto x Teste de queda

\begin{tabular}{c|c}
\hline Traço & $\begin{array}{c}\text { Teste de } \\
\text { queda } \mathbf{( c m})\end{array}$ \\
\hline Piloto & 14 \\
\hline $10 \%$ de $\mathrm{CBC}$ & 8 \\
\hline $20 \%$ de $\mathrm{CBC}$ & 5,5 \\
\hline $30 \%$ de $\mathrm{CBC}$ & 2 \\
\hline $40 \%$ de $\mathrm{CBC}$ & 0 \\
\hline
\end{tabular}

Fonte: Autores.

A queda diminuiu conforme 0 acréscimo de $C B C$ ao concreto, pois quando comparado o traço piloto com o de $10 \%$ de $C B C$ notou-se que a queda reduziu consideravelmente quase pela metade, de 14 $\mathrm{cm}$ para $8 \mathrm{~cm}$, apontado a causa devido a
CBC ter maior absorção de água do que a areia. Levando isso em consideração, não foi feito mais substituições a partir de $40 \%$ de CBC, uma vez que esse traço não apresentou trabalhabilidade com a queda de $0 \mathrm{~cm}$, dificultando sua confecção.

A resistência à compressão axial do concreto foi esperada uma resistência de 20 $\mathrm{MPa}$ aos 28 dias, para ser considerado um concreto estrutural. Com isso, foi realizado o traço piloto para analogia dos traços com substituições parciais de areia por cinza pesada do bagaço da cana-de-açúcar, obtendo assim a caracterização da propriedade mecânica do concreto, conforme a Figura 2.

Figura 2. Relação entre o traço e sua resistência de ruptura à compressão

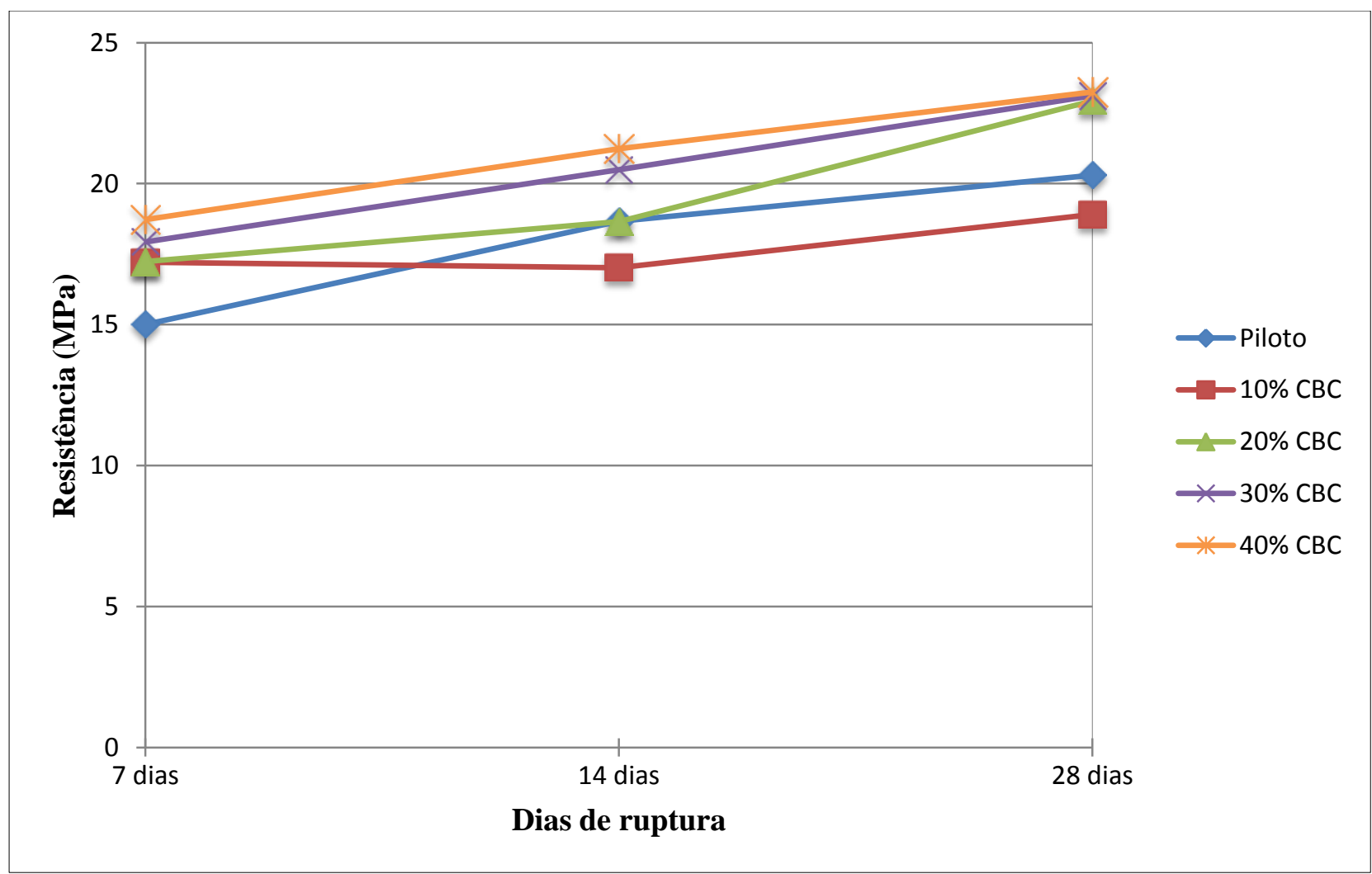

Fonte: Autores(2017). 
Através da Figura 2 expressamos as resistências à ruptura, em $\mathrm{MPa}$, atingidas para os traços Piloto, $10 \%, 20 \%, 30 \%$ e $40 \%$, aos 7, 14 e 28 dias, em que foi feito 3 corpos de prova para cada data de rompimento e realizada a média aritmética.

Com base nos dados apresentados pode-se observar que houve um aumento gradual da resistência à ruptura dos traços conforme o aumento parcial da substituição de areia por $C B C$, sendo assim todos os traços aos 28 dias apresentaram-se resistência de ruptura maior que $20 \mathrm{MPa}$, entretanto o de $10 \%$ apresentou uma perda de resistência, atribuída a um erro de adensamento da mistura no corpo de prova, pois pela projeção de crescimento do traço de $20 \%, 30 \%$ e $40 \%$ de $C B C$ a resistência à ruptura aumentou. Para demonstração de melhor resultado foi o de $40 \%$ considerado o traço ótimo com maior resistência à ruptura, com 23,25 MPa.

Quanto à absorção de água do concreto com $\mathrm{CBC}$ foi determinada conforme a ABNT NBR 9778:2009 por imersão em água, para assim determinação da porosidade do concreto com CBC, apontado na Tabela 11.
Tabela 11. Absorção de água

\begin{tabular}{c|c|c|c}
\hline Traço & $\begin{array}{c}\text { Massa } \\
\text { seca } \\
\mathbf{( k g )}\end{array}$ & $\begin{array}{c}\text { Massa } \\
\text { saturada } \\
\mathbf{( k g )}\end{array}$ & $\begin{array}{c}\text { Absorção } \\
\text { de água } \\
\mathbf{( \% )}\end{array}$ \\
\hline Piloto & 3,626 & 3,842 & 5,96 \\
\hline $10 \%$ & 3,668 & 3,894 & 6,16 \\
\hline $20 \%$ & 3,592 & 3,822 & 6,40 \\
\hline $30 \%$ & 3,526 & 3,750 & 6,35 \\
\hline $40 \%$ & 3,522 & 3,752 & 6,53 \\
\hline
\end{tabular}

Fonte: Autores.

Os traços apresentaram que quanto maior a porcentagem de $\mathrm{CBC}$, maior a absorção de água, salvo o traço de $30 \%$ que teve uma absorção de água um pouco menor que os traços $20 \%$ e $40 \%$ de CBC com $6,35 \%$.

\section{CONSIDERAÇÕES FINAIS}

A análise dos resultados físicos mostrou algumas diferenças entre a areia média e o material substituinte, contudo a CBC apresentou resultados satisfatórios e uma maior semelhança com a areia fina. Quanto à análise dos resultados mecânicos, observou-se que não apenas atinge a resistência de ruptura à compressão proposta como há um aumento gradual da mesma nos traços confeccionados com a $C B C$, ou seja, quanto maior quantidade de CBC mais resistência à ruptura foi apresentada, acontecendo à mesma coisa com a propriedade física de absorção de água dos traços analisados, quanto maior a substituição maior absorção. 
Portanto, constatou-se a viabilidade do material devido à eficácia da substituição parcial das cinzas como agregado miúdo no concreto estrutural, apresentando uma destinação viável economicamente e ambientalmente, reduzindo os impactos ambientais.

\section{AGRADECIMENTOS}

Agradecemos aos funcionários do Laboratório de Construção Civil da UNOESTE, pela paciência e contribuição nas experimentações.

\section{REFERÊNCIAS}

ALCARDE, A. R. Processamento da cana-deaçúcar: outros produtos. Agência de informação EMBRAPA. Disponível em: $<$ http://www.agencia.cnptia.embrapa.br/ges tor/cana-de-

acucar/arvore/CONTAG01_10822122006154

841.html\#>. Acesso em: 18 jun. 2016.

ASSOCIAÇÃO BRASILEIRA DE NORMAS TÉCNICAS. Agregados para concreto Especificação: NBR 7211. Rio de Janeiro, 2009.

ASSOCIAÇÃO BRASILEIRA DE NORMAS TÉCNICAS. Amostras de solo - Preparação para ensaios de compactação e ensaios de caracterização: NBR 6457. Rio de Janeiro, 1986.

ASSOCIAÇÃO BRASILEIRA DE NORMAS TÉCNICAS.Argamassa e concreto endurecidos - Determinação da absorção de água por imersão - Índice de vazios e massa específica: NBR 9778. Rio de Janeiro, 2009.

ASSOCIAÇÃO BRASILEIRA DE NORMAS TÉCNICAS. Concreto - Determinação da consistência pelo abatimento do tronco de cone: NBR NM 67. Rio de Janeiro, 1998.

ASSOCIAÇÃO BRASILEIRA DE NORMAS TÉCNICAS. Concreto - Ensaio de compressão de corpos-de-prova cilíndricos: NBR 5739. Rio de Janeiro, 2007.

ASSOCIAÇÃO BRASILEIRA DE NORMAS TÉCNICAS. Concreto - Procedimento para moldagem e cura de corpos de prova: NBR 5738. Rio de Janeiro, 2015.

ASSOCIAÇÃO BRASILEIRA DE NORMAS TÉCNICAS. Grãos de solos que passam na peneira de $4,8 \mathrm{~mm}$ Determinação da massa específica: NBR 6508. Rio de Janeiro, 1984.

ASSOCIAÇÃO BRASILEIRA DE NORMAS TÉCNICAS. Projetos de Estrutura de Concreto: NBR 6118. Rio de Janeiro, 2014.

ASSOCIAÇÃO BRASILEIRA DE NORMAS TÉCNICAS. Rochas e solos: NBR 6502. Rio de Janeiro, 1995.

ASSOCIAÇÃO BRASILEIRA DE NORMAS TÉCNICAS. Solo - Análise granulométrica: NBR 7181. Rio de Janeiro, 1988.

BRASIL. Ministério da Agricultura, Pecuária e Abastecimento. Cana-de-açúcar. $2012 . \quad$ Disponível em: $<$ http://www.agricultura.gov.br/vegetal/cult uras/canade-acucar>. Acesso em: 07 jul. 2016.

CAVALCANTI, V. M. M.; PARAHYBA, R. E. R.A Indústria De Agregados Para Construção Civil $\mathrm{Na}$ Região Metropolitana De Fortaleza. Brasília, 2012. Disponível em: <http://www.dnpm.gov.br>. Acesso em: 23 jun. 2016.

CONAB. Acompanhamento da Safra Brasileira: Cana-de-açúcar, 2015. Disponível em: <http://www.conab.gov.br/>. Acesso em: 17 jun. 2016. 
FIESP. Ampliação da Oferta de Energia Através da Biomassa. São Paulo, 2001. Disponível em: <http://www.fiesp.com.br>. Acesso em: 23 jun. 2016.

GURGEL, M. N. A. Tecnologia para aproveitamento de resíduos da agroindústria sucroalcooleira como biofertilizanteorganomineral granulado. 2012. 114 f. Tese (Doutorado) - Faculdade de Engenharia Agrícola, Universidade Estadual Paulista, Campinas-SP, 2012.

HOJO, L.Y.C. P; MARTINS, C.H. Utilização da substituição parcial do cimento por cinza leve do bagaço de cana-de-açúcar em concretos. 2015. Disponível em: <http://mixsustentavel.paginas.ufsc.br/files/ 2015/08/ARTIGO-11.pdf>. Acesso em: 17 jun. 2016.

PEREIRA, A. C. et al. Cimentoportland. 2013. Disponível em: <http://sinop.unemat.br/site_antigo/prof/fot o_p_downloads/fot_7092cimento_pobtland_ pdf.pdf>. Acesso em: 11 jul. 2016.

SALES, A; LIMA, S. A. Use of Brazilian sugarca ne bagasse ash in concrete as sand replace ment. Waste Management, v. 30, p. 11141122, 2010. https://doi.org/10.1016/i.wasman.2010.01.0 $\underline{26}$

SILVA, A. J. Estudo da viabilidade de utilização da cinza pesada em adição ao concreto compactado com rolo (CCR) destinado a camada de base de pavimentos híbridos. $2006 . \quad$ Disponível em: <https://repositorio.ufsc.br/bitstream/handl e/123456789/89471/232415.pdf?sequence= 1\&isAllowed=y>. Acesso em: 11 jul. 2016.

SILVA, G. R. Manual de Traços de Concreto. 3. ed. São Paulo: Nobel, 1975.

TEODORO, S. B. Avaliação do uso da areia de britagem na composição do concreto estrutural.

Disponível em:

<http://www.ufjf.br/engenhariacivil/files/20 12/10/TCC-AVALIA\%C3\%87\%C3\%830-DOUSO-DA-AREIA-DE-BRITAGEM-NACOMPOSI\%C3\%87\%C3\%830-DO-.pdf>. Acesso em: 11 jul. 2016.

TORRES, et al. Materiais Pozolânicos. 2010. Disponível em: <https://blogdopetcivil.com/tag/propriedade s-pozolanicas/>. Acesso em: 17 jun. 2016.

VALVERDE, F. M. Balanço Mineral Brasileiro. Extração de areia. Brasília, 2001. Disponível em: <http://www.dnpm.gov.br>. Acesso em: 26 jun. 2016. 